\title{
The Macroscopic Growth Laws of Brain Metastases
}

\author{
Beatriz Ocaña-Tienda ${ }^{1^{*}}$, Julián Pérez-Beteta ${ }^{1}$, David \\ Molina-García $^{1}$, Juan Jiménez-Sánchez ${ }^{1}$, Odelaisy Leon-Triana ${ }^{1}$, Ana \\ Ortiz de Mendivil ${ }^{2}$, Beatriz Asenjo ${ }^{3}$, David Albillo ${ }^{4}$, Luís \\ Pérez-Romasanta $^{5}$, Manuel Valiente ${ }^{6}$, Lucía Zhu ${ }^{6}$, Pedro García- \\ Gómez $^{6}$, Elisabeth González-Del Portillo ${ }^{5}$, Manuel Llorente ${ }^{4}$, Natalia \\ Carballo $^{4}$, Estanislao Arana ${ }^{7 \dagger}$ and Víctor M. Pérez-García ${ }^{1^{*} \dagger}$ \\ ${ }^{1}$ Mathematical Oncology Laboratory, University of Castilla-La Mancha, \\ Ciudad Real, Spain. \\ ${ }^{2}$ Department of Radiology, Sanchinarro University Hospital, HM Hospitales, \\ Madrid, Spain. \\ ${ }^{3}$ Department of Radiology, Hospital Regional Universitario Carlos Haya, \\ Málaga,Spain. \\ ${ }^{4}$ Radiology Unit, MD Anderson Cancer Center, Madrid,Spain. \\ ${ }^{5}$ Radiation Oncology Service, Salamanca University Hospital, \\ Salamanca,Spain. \\ ${ }^{6}$ Brain Metastasis Group, Spanish National Cancer Research Centre (CNIO), \\ Madrid, Spain. \\ ${ }^{7}$ Department of Radiology, Fundación Instituto Valenciano de Oncología, \\ Valencia, Spain.
}

*Corresponding author(s). E-mail(s): Beatriz.Ocana@uclm.es; Victor.PerezGarcia@uclm.es; †These authors were both co-senior authors of this work.

\footnotetext{
Abstract

Tumor growth is the result of the interplay of complex biological processes in a huge number of individual cells in a changing environment. Effective simple mathematical laws have been shown to describe tumor growth in vitro, or in animal models with bounded-growth dynamics accurately. However, results for human cancers in patients are scarce. The study mined a dataset of 1133 brain metastases (BMs) with longitudinal imaging follow-up, treated with radiosurgery (SRS) to find growth laws for untreated BMs, relapsing treated BMs, and
} 


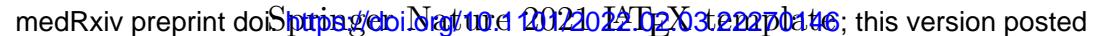

February 4, 2022. The copyright holder for this preprint (which was not certified by peer review) is the author/funder, who has granted medRxiv a license to display the preprint in perpetuity. All rights reserved. No reuse allowed without permission.

\begin{abstract}
radiation necrosis $(\mathrm{RN})$. Untreated BMs showed sustained growth acceleration, most likely related to the underlying evolutionary dynamics. Relapsing BM growth was slower, most probably due to a reduction in tumor heterogeneity after SRS, which may limit the evolutionary possibilities of the tumor. RN lesions had significantly larger growth exponents than relapsing BMs, providing a way to differentiate them from true progression. This may help in solving a problem of clinical relevance, since the first condition may resolve spontaneously, and not require further work-up, while the second requires therapeutic action.
\end{abstract}

Keywords: Brain metastases, mathematical oncology, radiation necrosis, tumor growth dynamic, radiosurgery

\title{
1 Introduction
}

Macroscopic tumor growth is a complex process resulting from the interplay of different biological elements at the cellular and subcellular levels. These include the driving molecular alterations and their associated heterogeneity, angiogenesis, the immune system, the tumor microenvironment, and surrounding healthy structures, the effect of treatments on the different tumor phenotypes/genotypes, etc.

Mathematical growth laws have been shown to describe longitudinal tumor growth dynamics effectively in simple experimental models. A great deal of data is available for those models, which do not have the biological complexity of human tumors [1-5]. Describing cancer growth in humans is far more difficult because of the different biological mechanisms that drive it over distinct tumor stages.

Assessing complex tumor growth dynamics over time, given the great variability of phenotype and genotype, is very difficult with current techniques. Medical images are performed routinely in most cancer patients and provide rough global macroscopic information -the so-called imaging phenotype- which integrates the several processes occurring at the microscale, potentially providing information on the underlying tumor biology.

Longitudinal datasets for untreated malignant tumors are rare, and of limited quality, since therapeutic action is typically performed promptly. This is why studies of untreated tumor growth laws in humans have been limited to the use of two time points $[6,7]$. Only recently has a study using more time points shown superexponential dynamics, as a result of the evolutionary dynamics in human cancers [8].

Brain metastases (BMs) are the most common intracranial tumor and a major complication of many cancers, with $20 \%-30 \%$ of cancer patients developing BMs in the course of their disease $[9,10]$.

In this study, the goal was to look at the growth dynamics of untreated BMs using mathematical methods and a huge patient database with longitudinal imaging followup. It was also desired to know whether there was a measurable effect on the growth dynamics of the expected loss of tumor heterogeneity after treatment. Treatment options for BMs are surgery, whole brain radiation therapy (WBRT), gamma knife radiosurgery, stereotactic radiosurgery (SRS), targeted and systemic therapies. 


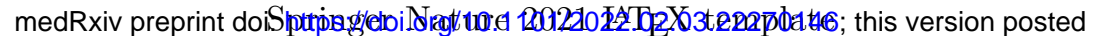

February 4, 2022. The copyright holder for this preprint (which was not certified by peer review) is the author/funder, who has granted medRxiv a license to display the preprint in perpetuity. All rights reserved. No reuse allowed without permisșion. The Macroscopic Growth Laws of Brain Metastases

A further aim was to study whether mathematical models could differentiate between the growth patterns of tumor relapse and radiation necrosis (RN). Radiation Necrosis is a side effect of SRS and leads to longitudinal inflammatory growth on MR images that may resolve spontaneously. This leads to a diagnostic dilemma due to their similarities on MR imaging with tumor recurrence [11-14].

\section{Results}

\subsection{BM longitudinal growth dynamics}

The Von-Bertalanffy model [15]

$$
\frac{d V}{d t}=\alpha V^{\beta}-b V
$$

has been proven recently to describe the longitudinal dynamics of growing human tumors [8]. It has been argued, and supported with data from human cancers, that malignant tumors with heterogeneous clonal composition have exponents $\beta>1$. The reason is that there would be selection for more aggressive phenotypes/genotypes, leading to an acceleration of the growth rate, which would manifest in the form of super-exponential unbounded growth. This paper will focus on growing tumors for which the first term in Eq. (1) dominates over the second. In this context, it will be assumed that $b \simeq 0$, meaning that most of the metabolic requirements are routed towards biosynthesis rather than basal energy consumption. Moreover, our dataset having time intervals with three consecutive longitudinal measurements without treament $\left(V_{0}, V_{1}, V_{2}\right)$ allows us to identify at most three parameters for each tumor $\left(V_{0}, \alpha, \beta\right)$ but not more. When $b$ is assumed to be zero, for a clonally homogeneous tumor with only a fraction of the cells proliferating due to necrosis, nutrient limitations, etc., one would get exponents $0<\beta<1$, i.e. below exponential growth, but still increasing with time.

Three patient groups were studied in a first batch of analyses. They included the cases of (i) growing untreated and (ii) relapsing post-radiotherapy BMs, and also (iii) growing BMs from patients under chemotherapy (CT) but with no specific treatment for the BMs. Patients in the last group included only drugs crossing the bloodbrain-barrier (BBB) as described in 'Methods'. Figure 1(a,b) shows examples of BM longitudinal growth dynamics as observed in MRI studies. The growth exponent $\beta$ governing the dynamic for each patient was obtained as described in the Methods section. The median value of the fitted individual exponents for untreated BMs $(N=$ 10) was $\beta=1.59$. This suggests substantial growth acceleration with $\beta \simeq 3 / 2$. It is interesting to note that this number differs from the value $5 / 4$ obtained from metabolic scaling data of primary tumors [8].

Median growth exponent for BMs growing under CT was $\beta=0.64(N=16)$. For BMs growing after completing radiation therapy (RT) we obtained $\beta=0.72$ $(N=23)$. Finally, for those having received RT and under CT we got $\beta=0.68$ $(N=33)$, where RT can stand for WBRT, SRS or a combination of both. Box plots are shown in Fig. 1(c). Similar growth exponents after receiving different RT modalities were shown (see Fig. 1 (d)). Thus, volumetric growth of treated BMs had lower $\beta$ exponents on average than those obtained for untreated BMs.

To investigate whether animal models display similar behavior in the growth of untreated BMs, experiments in mouse models were performed as described in 'Methods'. The median value of the individual exponents $\beta$ was 1.44 (interquartile range: $1.34,1.57)$ (Fig. $1(\mathrm{e}, \mathrm{f}))$. 

is the author/funder, who has granted medRxiv a license to display the preprint in perpetuity. All rights reserved. No reuse allowed without permission.

Since each dataset had a small number of patients for which only three time points were available to obtain three parameters, the fitting method could be sensitive to small variations in the data. This led to a broad spread in the values of the individual patient parameters obtained. An alternative approach to obtaining $\beta$ was thus designed by looking for the value that provided the best fit for all patients in each subgroup (untreated, relapsing post-SRS, growing while in CT treatment and $\mathrm{RNs}$ ). The absolute errors weighted by volume, and the relative errors, were computed for each $\beta$ value and all groups of patients simultaneously as described in 'Methods'. The results for the different datasets are summarized in Fig. $1(\mathrm{~g}, \mathrm{~h})$. The exponent best fitting the dataset of untreated BMs was $\beta_{*}=1.5$. For treated relapsing tumors, the best fit was obtained with $\beta_{*}=0.51(\mathrm{CT})$ and $\beta_{*}=0.71$ (SRS), showing again a slowing down of the growth dynamics. Figure $1(\mathrm{~g})$ shows the error weighted by the volume (relative error) for each BM and value of $\beta$. Figure $1(\mathrm{~h})$ shows the sum of the errors for all the BMs included in each group as a function of $\beta$.

\subsection{Evolutionary dynamics of tumor complexity}

It is known that cancer treatments lead to a reduction of the clonal complexity at the point of maximal response, due to the selective pressures exerted by the therapies [1619]. One would expect reduction to be reflected in the growth dynamics exponents of BMs as observed in our previous analysis.

To illustrate how treatment could modulate heterogeneity and influence the $\beta$ values obtained from BM longitudinal growth data, the evolution of ideal BMs was simulated with a simple structure composed of two different clonal populations. This was done by adapting the mesoscopic model of Ref. [20] to two competing populations sharing space and resources as described in 'Methods'. The initially most abundant population proliferated and migrated at fixed rates, while the least abundant population had an advantage in both processes, and hence was assumed to be more aggressive, due to either mutational changes or irreversible phenotype changes, providing evolutionary benefits. In that way we accounted for an initial tumor heterogeneity, and competition between the two populations was sustained during the early follow-up, several months post SRS.

An example is shown in Fig. 2(a). The untreated situation was started with a small fraction (10\%) of an aggressive population coexisting with a larger population of less aggressive cells. After a few months, the tumor was substantially enriched in silico in the most aggressive population (94\% versus $6 \%$ ) and the growth exponent $\beta$ was found to be $\beta=1.53$.

In a second set of numerical experiments, initially growing tumors were treated in silico with SRS with a differential effect on the two subpopulations. First, one or other of the subpopulations was assumed to be very sensitive to SRS, so that one of the populations was completely depleted. In both scenarios, depicted in Fig. 2 (b,d) growth exponents were respectively $\beta=0.63$ and $\beta=0.68$, thus far from even exponential growth. A third scenario assumed the most aggressive population to be more sensitive to treatment, thus restoring equilibrium between the two subpopulations. In this scenario, the growth exponent found was $\beta=1.01$, still far from super-exponential. 

is the author/funder, who has granted medRxiv a license to display the preprint in perpetuity. All rights reserved. No reuse allowed without permission. The Macroscopic Growth Laws of Brain Metastases

\subsection{Radiation necrosis events displayed the fastest growth dynamics, allowing them to be discriminated from recurrent tumors}

The next stage was to study the growth dynamics of RN events. Usually these lesions increase in size, due to inflammatory changes after SRS, and regress spontaneously, requiring no further aggressive therapeutic action (an example is shown in Fig. 3(a)). Tumor recurrences have a very similar growth pattern but may require prompt therapeutic action, typically in the form of brain surgery or re-irradiation when appropriate.

The differences between the fitting exponents of the groups of relapsing BMs and RNs were studied. The growing segment of the curve in $\mathrm{RN}$ events was first fitted to Eq. (1) as described in 'Methods'. The mean value of the growth exponent for the $24 \mathrm{RN}$ events included in the study was found to be $\beta=2.54$. The Kruskal-Wallis test for the comparison between the RN and groups with post-SRS relapse led to significant differences $(p=0.002)$. The box plot in Fig. 3(b) shows this comparison. The group fitting procedure described in 'Methods' was performed for this dataset, giving $\beta_{*}=2.4$ for the group of RNs (see Fig. 1 (g4,h4)).

Thus, RN events displayed a very fast growth dynamic, faster indeed than that of BM recurrence post-SRS. It is thus hypothesized that the differences in growth dynamics could be used to discriminate between the two groups. The area under the ROC curve (AUC) in Figure 3(d) illustrates the ability of the exponent $\beta$ obtained from longitudinal growth data to classify events either as $\mathrm{RN}$ events or recurrences. The result obtained was $\mathrm{AUC}=0.749$, with 0.78 sensitivity and 0.7 specificity. Based on the mathematical understanding of tumor growth dynamics, this metric therefore has the ability to complement other evidence in differentiating RNs from post-SRS BM recurrence.

The calculation of the growth exponent $\beta$ requires three consecutive MR images with volume increase. However, only two follow-ups are usually available in the clinical practice at the time of decision. It was considered whether the volumetric increase rate obtained from only two consecutive MRIs would be able to discriminate between RNs and BM recurrence. The analysis was performed as described in 'Methods'. Although RN growth rates were in general larger as measured by the volumetric increase between two time points, the difference with the group of RNs was statistically non-significant $(p=0.142)$. Figure $3(\mathrm{c})$ shows the box plots of both groups.

It is striking that RN events led to faster growth dynamics, and correspondingly larger growth exponents according to (1), than either untreated or relapsing BMs. To gain some insight as to why this happened, mathematical methods were used. First, an ordinary differential-equation-based compartmental mathematical model was put together accounting for the necrosis induced by SRS and the inflammatory response given by Eqs. (7) as described in 'Methods'.

The model was fitted to our dataset, which led to individual parameter values with very good fits to the data (six examples are shown in Fig. 3(e)). Then different initial volumes were taken, ranging from 0.5 to $3.0 \mathrm{~cm}^{3}$, and $500 \mathrm{RN}$ events per volume were simulated in silico, allowing the model parameters to take random values within the range of the data. Results for the mean exponents are shown in Supplementary Table S2. Regardless of the model parameters and initial volumes, the mean $\beta$ values obtained from the mathematical model were always greater than 2. This dynamic due to inflammation is reminiscent of other processes mediated by 

is the author/funder, who has granted medRxiv a license to display the preprint in perpetuity.

immune response, such as treatments with CAR T-cells, also showing a very fast initial expansion of the immune compartment [21, 22].

The mathematical model used for the previous analysis included only a few biological elements of relevance. A more complete study was designed using a stochastic mesoscale brain metastasis growth simulator. The simulator was set up using the biological rules described in 'Methods'. A total of 400 simulations were performed of virtual BMs treated with SRS displaying growth after treatment and calculated the exponent $\beta$ as described in Supplementary Information Section 1D. The response of two different groups was simulated. First, a control group of 200 BMs assuming no damage to the healthy tissue surrounding the lesions. A second group accounted for the damage induced by SRS to normal brain tissue next to the BMs. The latter would be the situation expected in clinical practice. Results for the values of $\beta$ calculated are shown in Figure 3(f). For the first group, the $\beta$ values obtained were typically below 1 (Fig. 3(f1)). This exponent describes the dynamics of relapsing lesions. For the group including damage to the healthy tissue there would be two expected behaviors. In cases where SRS eliminates most of the tumor cells regrowth is due to the inflammatory component, while for larger tumor remnants regrowth is an indication of tumor recurrence. Figure 3(f2) provides the scaling exponents obtained for the group of in-silico radiation necrosis events. Median values of $\beta>1$ were obtained typically for radiation necroses in silico, while exponents $\beta<1$ characterized the dynamics of tumor recurrence (Fig. $3(\mathrm{~g})$ ).

Thus, in line with our previous experimental observations, the question of whether the value of $\beta$ obtained from the synthetic data could be used to differentiate between inflammatory response and tumor progression was tested in silico. Figures $3(\mathrm{~g}-\mathrm{h})$ summarizes the results. Figure $3(\mathrm{~g})$ shows the box plots with the comparison between the groups. The ROC curve in Fig. 3(h) shows an optimal threshold that maximizes the sensitivity and specificity values of $\beta_{*}=1.05$ with a high value of $\mathrm{AUC}=0.97$.

\section{Discussion}

Evolution is one of the main driving forces of life on Earth and is behind the observed diversity at every level of biological organization. Evolutionary processes are used by cancers to survive within their hosts and escape from the pressures exerted by treatments. It is a remarkable fact that the growth laws of untreated human malignant cancers and their animal model counterparts display a signature of the evolutionary processes taking place behind the scenes, in the form of an exponent $\beta>1$ in (1).

This study mined a huge dataset to test such a surprising result over a time scale of months, i.e. the time interval spanning three MRI studies (6-9 months). BMs have a background of heterogeneity that could provide the necessary substrate for evolutionary competitive dynamics to happen, leading to super-exponential growth of the tumor mass. Phylogenetic analyses have revealed that BM-competent clones genetically diverge from their primary tumors at a relatively early stage in lung adenocarcinoma patients [23]. Genomic analyses of solid tumors and matched BMs revealed significant genetic heterogeneity between primary lesions and BMs [24], and the degree of genetic heterogeneity of BMs varied significantly among individuals with NSCLC, breast, and colorectal cancer [25-27]. In addition to the genetic heterogeneity, BMs have significant epigenetic variability $[28,29]$ and there can be other phenotype-based mechanisms playing a role [30]. 

is the author/funder, who has granted medRxiv a license to display the preprint in perpetuity. All rights reserved. No reuse allowed without permisșion. The Macroscopic Growth Laws of Brain Metastases

Our results manifested both a macroscopic reflection of the evolutionary dynamics in the form of a $\beta>1$ exponent for pre-treatment longitudinal dynamics, and also the loss of biological richness experienced by BMs after therapy, which lead to the substantially reduced exponents $\beta_{*}=0.71$ post-SRS. It has been hypothesized, using mathematical models, that treatment strategies in which an oncological "first strike" reduces the size and heterogeneity of the population, then followed by "second strikes" could lead to cancer extinction in metastatic disease [31, 32]. Our results show the effectiveness of the first-line SRS approach in providing an ecoevolutionary first-strike strategy for BMs. Independently of the volumetric reduction observed, which ends up being marginally irrelevant if the tumor recurs, the substantial reduction of the growth exponent implies a direct effect on the tumor ecological complexity. In the case of BMs, "second-strike" strategies could be provided by targeted therapies with better penetration than classical drugs across the blood-brain barrier, many of which are under investigation [33, 34].

It may seem naively counterintuitive that BMs subject to different treatment modalities (SRS, WBRT, CT) led to similar growth exponents $\beta$, since SRS is known to be substantially more effective than WBRT or CT. Our retrospective study focused only on BMs growing after (RT) or under (CT) treatment, but of course there would be many BMs with complete response, e.g. to SRS, that were not included here. It is also relevant to emphasize that the growth exponent cannot be directly interpreted as a growth rate, e.g. the speed of volumetric growth, but as a measure of the shape of the tumor growth curve.

An intriguing result of our study was that the growth exponent for untreated BMs was close to $3 / 2$. It has recently been found for different primary tumors, lung (both adenocarcinoma and squamous cell), breast, colorectal, glioma, and head and neck cancer, that metabolic scaling exponents were very close to $5 / 4$ [8]. Following the classical reasoning of West et al. [35], one would expect metabolic exponents to be the same as growth exponents. This raises the interesting question of what the metabolic scaling of BMs would be at diagnosis, since the datasets of [8] did not include that condition. Would it be $3 / 2$, raising the question of why BMs have a different metabolic scaling than other cancers? Or would it be $5 / 4$, raising the question of why there should be a mismatch between metabolic and growth exponents in BMs?

Several authors have wondered whether the interval between SRS planning and treatment is accurate [37-40]. In order to study this, they compared volumes from diagnostic imaging and radiosurgery planning MRI and extrapolated the growth linearly to the day of SRS, since only two time points were available. Progression between diagnosis and SRS is common, and some suggest that a mathematical model would be useful to individualize treatments. Our model based on three time points shows that the growth exponent of untreated BMs increases with time, thus pointing to a potential substantial benefit of reducing the interval between SRS planning and treatment.

Our study also sheds light on practical questions of relevance in neuro-radiology. First of all, previous studies have proposed that the observation of volumetric growth over two or more sequential follow-up images after SRS spaced more than three months apart could be a signature of tumor recurrence [41]. However, all of our RN events satisfied this condition and were obviously not relapses.

Secondly, it was found that when three consecutive MRI studies are available, computing $\beta$ could allow lesions to be classified on the basis of their growth dynamics as either RNs or BM recurrences. The recommended interval between MRI studies 


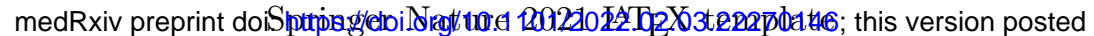

February 4, 2022. The copyright holder for this preprint (which was not certified by peer review) is the author/funder, who has granted medRxiv a license to display the preprint in perpetuity. All rights reserved. No reuse allowed without permission.

is 2-3 months [42], but in our dataset most imaging studies were performed every three months. This raises the question of whether the standard monitoring interval between MRIs could be suboptimal for BM patients with controlled extracranial disease. Our study suggests that in these patients a time interval of two months could help in making an informed decision on potential relapse in the same time window of six months used currently, but with three data points rather than only two.

Our study had several strengths. First, a review was conducted on a substantial dataset of 1133 BMs treated with SRS with high-resolution data, according to the guidelines for BM clinical studies [36]. Beyond their fundamental value, our results also have practical implications. Upon recurrence after SRS, physicians have the possibility of adding new lines of treatment, most notably surgery when the primary tumor and possibly other metastases are under control. However, RNs may resolve spontaneously and require no further therapy. Discriminating RNs from recurrence radiologically is often a difficult task [11-14], but is necessary to find the best therapeutic course of action. Due to diagnostic difficulties on a growing lesion, biopsy remains the gold standard [14], hampered by its invasiveness and with no clear-cut diagnostic criteria, where mixed histology is frequently encountered. This suggest a span of evolution where decreasing irradiated metastatic cells coexist with RN.

The main limitation of our study was that only a subset of $106 \mathrm{BMs}$ of the whole 1133 BMs could be used for the computation of $\beta$. Only this part of the data had the three sequential imaging studies displaying sustained growth and with no further therapeutic actions performed in that time window required to compute the growth exponents. Because of the size of the dataset the data could not be analyzed via primary histologies. It would be very interesting to look at whether any of the conclusions of our study depend on the type of primary cancer considered.

In summary, we studied a large BM dataset and showed a continuous acceleration of growth, due to Darwinian competition between different tumor subpopulations. BMs relapsing after treatment displayed slower growth, compatible with treatmentmediated reduction of tumor heterogeneity. The longitudinal growth dynamic of radiation necrosis, an inflammatory side effect of radiation therapy, was much faster. This reflects its inflammatory nature and means it can be distinguished from a relapsing tumor, which is helpful in the clinical setting in discriminating between $\mathrm{RN}$ and tumor relapse.

\section{Methods}

\section{Patients}

Patients included were all participants in the study MetMath (Metastasis and Mathematics), a retrospective, multicenter, nonrandomized study approved by five hospitals (blinded for review). All patients were diagnosed with BM in the period 2007-2021 and followed up with MRI according to standard clinical practice. A total of 354 patients who received SRS at any time during the evolution of the disease, and with full longitudinal follow-up, were reviewed in the study, including 1133 BMs. Primary tumor histologies were mainly non-small-cell lung cancer (NSCLC), breast cancer, melanoma and SCLC.

For the study of longitudinal volumetric dynamics, BMs were selected from the MetMath dataset on the basis of several inclusion criteria: 1) A minimum of three 


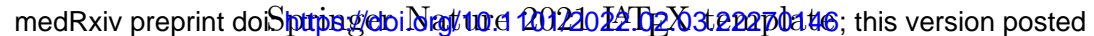

February 4, 2022. The copyright holder for this preprint (which was not certified by peer review) is the author/funder, who has granted medRxiv a license to display the preprint in perpetuity. All rights reserved. No reuse allowed without permisșion. The Macroscopic Growth Laws of Brain Metastases

consecutive imaging studies, including a volumetric contrast-enhanced (CE) T1weighted MRI sequence (slice thickness $\leq 2.00 \mathrm{~mm}$, no gap) with no substantial imaging artifacts, at different time points, were required in order to allow for reliable fittings of the tumor growth model (1). 2) An increase in tumor volume at each of the three time points was required, since it was desired to study the growth of either untreated or recurrent tumors, or radiation necrosis events. 3) Only time points without previous SRS/WBRT treatments or with SRS/WBRT treatments received more than four months before the first imaging study were considered, in order to exclude the potential confounding effect of acute inflammatory responses seen in some patients in the first MRI after SRS, which disappeared at the second follow-up (Supplementary Fig. S5). 4) Patients with prior surgical resection of the metastasis were excluded to avoid confounding effects, such as ischemia. 5) Brain metastases lacking relevant clinical variables and/or treatment regime, as well as those lacking consensus in segmentation were also excluded. 6) Patients were included regardless of their systemic treatment; however, BMs were considered as untreated for patients who were receiving CTs which are unable to cross the blood-brain-barrier (BBB) such as pertuzumab or trastuzumab [43, 44]. A list of CT drugs received by patients in the study is available in Supplementary Table S3.

To ensure that every BM met the inclusion criteria, each was carefully revised, with lesion segmentation being necessary in some cases to assess its growth dynamics. Finally, $106 \mathrm{BMs}$ from 77 patients were included in the study. Of these, 10 were untreated, 16 had received chemotherapy (CT), 23 WBRT or SRS (RT), 33 received both treatments, and 24 were diagnosed with radiation necrosis (RN). A summary of patient characteristics is provided in Supplementary Table S4.

The diagnosis of radiation necrosis was made according to the RANO criteria [45] when the lesion showed: 1) increased T1 contrast enhancement located in the irradiated area with central hypointensity and increased peripheral edema; 2) substantial regression or stability (for $\geq 4$ months) of enhancing areas on serial follow-up MRI scans without additional treatment or after bevacizumab; 3) reduced relative cerebral blood volume (rCBV) and F-18 fluorodeoxyglucose (FDG) in the absence of any highly vascularized nodular area within the contrast-enhanced MR images of the lesion [46].

\section{Imaging and Follow-Up}

The volumetric contrast-enhanced T1-weighted MR imaging sequence used to delineate the BMs and compute their volumes was gradient echo using 3D spoiled gradient-recalled echo or 3D fast-field echo after intravenous administration of a single dose of gadobenate dimeglumine $(0.10 \mathrm{mmol} / \mathrm{kg})$ with a 6 -to 8 -minute delay. MRI studies were performed in the axial or sagittal plane with a $1.0 \mathrm{~T}(n=5), 1.5 \mathrm{~T}$ $(n=357)$ or $3.0 \mathrm{~T}(n=55) \mathrm{MR}$ imaging unit. Imaging parameters were no gap, slice thickness of $0.52-2.0 \mathrm{~mm}$ (mean $1.3 \mathrm{~mm}$ ), $0.4-1.1 \mathrm{~mm}$ (mean $0.5 \mathrm{~mm}$ ) pixel-spacing and $0.42 .0 \mathrm{~mm}$ spacing between slices (mean $1.0 \mathrm{~mm}$ ).

Typical time spacing between MRI studies for BM follow-up was about 3 months for the institutions participating in the study. In our dataset, the median time between the first two MRI studies was 3.04 months while for the second it was 2.64 months. 


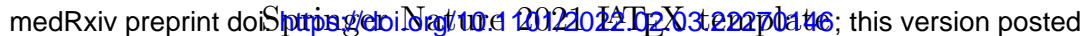

February 4, 2022. The copyright holder for this preprint (which was not certified by peer review) is the author/funder, who has granted medRxiv a license to display the preprint in perpetuity.

All rights reserved. No reuse allowed without permission.

\section{Tumor Segmentation}

T1-weighted images were retrospectively analyzed by the same image expert (B.O.T.) and reviewed by both an image expert with more than 6 years of expertise in tumor segmentation (J.P.-B., D.M.-G. or V.M.P.-G.) and a senior radiologist with 27 years of experience (E.A.). Segmentations were performed by importing the DICOM files into the scientific software package MATLAB (R2019b, The MathWorks, Inc., Natick, MA, USA). Each BM lesion was automatically delineated using a graylevel threshold chosen to identify the CE tumor volume. Segmentations were then corrected manually, slice by slice, using an in-house software as described in [47]. Necrotic tissue was defined as hypointense tumor regions inside CE tissue. CE and necrotic areas of the lesions were reconstructed, the tumor interfaces rendered in 3D. Tumor volume was computed as the volume within the surface delimiting CE areas.

\section{Statistical Analysis}

Statistical analyses were performed using the MATLAB software, and also SPSS (Statistical package for the Social Sciences, v24.00 IBM) software. The normality of the variables was assessed via the Kolmogorov-Smirnov test. The KruskalWallis test was conducted with adjustment for multiple comparisons, to determine statistically significant differences for non-parametric data (the scaling law growth factor, $\beta$ ). Pvalues smaller than 0.05 were considered to be statistically significant. A ROC curve was built in SPSS in order to establish how good a BM classification would be.

\section{Animal studies with H2030-BrM3 cells}

The human lung adenocarcinoma brain tropic model H2030-BrM3 (abbreviated as H2030-BrM) [48] was injected into the hearts of nude mice to induce the formation of brain metastasis from systemically disseminated cancer cells. Brain colonization and growth of metastasis were traced using non-invasive bioluminescence imaging, as BrM cells express luciferase. On administration of the substrate D-luciferin, bioluminescence generated by cancer cells was measured over the course of the disease. The increase in photon flux values is a well-established correlate of tumor growth in vivo [48]. The experiments were performed in accordance with a protocol approved by the Centro Nacional de Investigaciones Oncolgicas (CNIO), the Instituto de Salud Carlos III and the Comunidad de Madrid Institutional Animal Care and Use Committee. Athymic nu/nu mice (Harlan) aged 46 weeks were used. Brain colonization assays were performed by the injection into the left ventricle of $100 \mu \mathrm{l}$ of PBS containing 100,000 cancer cells. Mice anaesthetized with isofluorane were injected retro-orbitally with D-luciferin $\left(150 \mathrm{mg} \mathrm{kg}^{-1}\right)$ and imaged with an IVIS Xenogen machine (Caliper Life Sciences). A bioluminescence analysis was performed using Living Image software (v.3).

\section{Cell culture}

H2030-BrM was cultured in an RPMI1640 medium supplemented with 10\% FBS, 2 $\mathrm{mM}$ l-glutamine, $100 \mathrm{IU} \mathrm{ml}^{-1}$ penicillin-streptomycin and $1 \mathrm{mg} \mathrm{ml}^{-1}$ amphotericin B. 


\section{Longitudinal growth analysis: individual growth exponents}

Solving (1), with $b=0$ gives

$$
\frac{V(t)^{-\beta+1}}{-\beta+1}-\frac{V_{0}^{-\beta+1}}{-\beta+1}=\alpha\left(t-t_{0}\right),
$$

Since there is information about the dynamics at three time points $\left(t_{0}, V_{0}\right)$, $\left(t_{1}, V_{1}\right)$ and $\left(t_{2}, V_{2}\right)$ obtained by image segmentation, the two parameters $\alpha$ and $\beta$ can be completely determined by evaluating (2) at the times $t_{1}, t_{2}$, giving

$$
\frac{1-\left(V_{1} / V_{0}\right)^{-\beta+1}}{1-\left(V_{2} / V_{0}\right)^{-\beta+1}}=\frac{t_{1}-t_{0}}{t_{2}-t_{0}},
$$

Eq. (3) is an algebraic equation for $\beta$ that was solved using the MATLAB function fzero (which returns the root of a nonlinear function) for each set of known values $V_{0}, V_{1}, V_{2}, t_{0}, t_{1}, t_{2}$.

In order to ensure that small changes in measured volumes do not affect the value of the computed $\beta$, an analysis of sensitivity was performed as described in Supplementary Information Section 2.

To compute the growth rate from two imaging studies $\left(t_{1}, V_{1}\right),\left(t_{2}, V_{2}\right)$ an exponential model was used to fit the last two points, i.e.

$$
V_{2}=V_{1} e^{\lambda\left(t_{2}-t_{1}\right)},
$$

the $\lambda$ exponent was computed for each metastasis, and used to discriminate between groups of relapses post-SRS and RN.

\section{Growth exponent interpretation}

The growth exponent $\beta$ provides information on the shape of the tumor growth curve. Figure 4(a) shows examples fitting the same pair of volumes/time points, with different values of $\beta$.

Thus, the growth exponent $\beta$ cannot be directly interpreted as a growth rate, e.g. the speed of volumetric growth. Figure 4(b) shows that any fixed value of $\beta$ (chosen there arbitrarily as $\beta=1$, i.e. exponential growth), is compatible with different 'growth rates'.

\section{Longitudinal growth analysis: individual growth exponents for mice}

In animals, more than three volumetric points are available, a different method was used to calculate the growth exponent for each mouse. Measurements at 7, 14, 18, 21, 25 and 28 days were usable from 24 mice, however at 25 and 28 days, the measured volume was close to the total brain volume and it was assumed that growth would be affected by limitations of space. Thus, to avoid confounding effects coming from mechanical constraints, the latter two time points were excluded from the analysis. A discretization of Eq. (1) was performed, and taking logarithms on both sides

$$
\ln \left(\frac{V_{i}-V_{i-1}}{t_{i}-t_{i-1}}\right)=\ln \alpha+\beta \ln V_{i},
$$




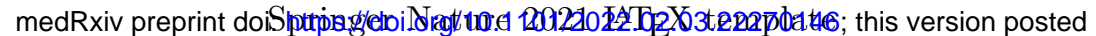

February 4, 2022. The copyright holder for this preprint (which was not certified by peer review) is the author/funder, who has granted medRxiv a license to display the preprint in perpetuity. All rights reserved. No reuse allowed without permission.

the slope of the straight line that best fits all the points for each mouse corresponds to the growth exponent $\beta$. Four mice were excluded because of volume decrease, leading to the use of 20 mice for $\beta$ computation.

\section{Longitudinal growth exponents: Group calculations}

An iterative method was used to automatically compute the optimum $\beta_{*}$, that is, the one giving the lowest relative error to the segmented volumes for each group.A sweep was performed on $\beta^{\prime}=[0,3]$ with 300 steps and on $V_{0}^{\prime}=\left[0, V_{1}\right]$ and $V_{1}^{\prime}=\left[V_{0}, V_{2}\right]$, with 500 steps for each. To each $\beta^{\prime}$ and each pair $\left(V_{0}^{\prime}, V_{1}^{\prime}\right)$ there corresponds a single value of $V_{2}^{\prime}$ from Eq. ( 3 ). Then, the sum of relative errors of the three segmented volumes for every BM $\left(V_{0}, V_{1}, V_{2}\right)$ was computed using the formula:

$$
\text { Rel. error }=\frac{\left|V_{0}^{\prime}-V_{0}\right|}{V_{0}}+\frac{\left|V_{1}^{\prime}-V_{1}\right|}{V_{1}}+\frac{\left|V_{2}^{\prime}-V_{2}\right|}{V_{2}},
$$

the smallest is retained, that is to say, the combination of $\left(V_{0}^{\prime}, V_{1}^{\prime}, V_{2}^{\prime}\right)$ that best fits $\left(V_{0}, V_{1}, V_{2}\right)$, given each $\beta^{\prime}$ (pseudocolor plots in Fig. $1(\mathrm{~g})$.) Finally, the $\beta_{*}$ value for which the sum of all errors (Fig. 1(h)) is minimum and therefore corresponds to the best fit for the whole subgroup, is observed.

\section{Mathematical model}

A mathematical model was constructed which describes RN events mathematically, given by the following equations.

$$
\begin{aligned}
& \frac{d N}{d t}=H-\lambda_{N} I, \\
& \frac{d I}{d t}=\gamma N I-\lambda_{I} I,
\end{aligned}
$$

Where $N(t)$ gives the evolution over time of the population of necrotic cells within the lesion and $I(t)$ the immune cells governing the inflammatory process. SRS was assumed to affect a region of healthy tissue contiguous to the tumor, where $H_{T}$ cells would be killed by radiation and become necrotic at a time $t_{N}$ after the SRS as

$$
H(t)=\frac{H_{T}}{t_{N}} \cdot U\left(t_{N}-t\right)
$$

where $U(x)$ is the Heaviside step function. This study considered $t_{N}$ to be around two months. The first term in (7a) accounts for the dynamics of healthy cells killed by the late effect of radiation as given by (8). The second term in (7a) represents necrotic cells cleared away by immune cells $(I(t))$. (7b) assumes that the immune response is stimulated by the presence of necrotic cells, and that immune cells have a death rate $\lambda_{I}$ (second term).

The parameter $\lambda_{I}$ corresponds to the immune-cell death rate, and was fixed at 0.07 days $^{-1}$, around two weeks $[49,50]$. Parameters $\lambda_{N}$ and $\gamma$ were estimated by fitting the model to the available longitudinal volumetric data by using the MATLAB functions fminsearch and ode45 functions returning values in the range $[0.0004-$ 0.007 days $^{-1}$, and $\left[6.1 \times 10^{-9}, 1.3 \times 10^{-7}\right]$ days $^{-1} \cdot$ cells $^{-1}$, for $\lambda_{N}$ and $\gamma$, respectively (see Supplementary Table S5 for the particular values for each fit).

The model (7) was used, together with the previously-obtained parameter range to explore the parameters $\beta$ that would be obtained in the context of the model in silico. A dataset of virtual BMs was generated in order to do this. For each choice 


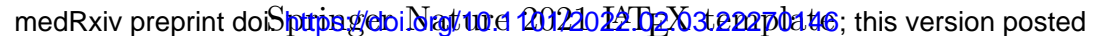

February 4, 2022. The copyright holder for this preprint (which was not certified by peer review) is the author/funder, who has granted medRxiv a license to display the preprint in perpetuity.

All rights reserved. No reuse allowed without permission.

The Macroscopic Growth Laws of Brain Metastases

of the various initial volumes $V_{0}=0.5,1.0,1.5,2.0,2.5$ and $3.0 \mathrm{~cm}^{3}, 500$ virtual BMs were generated by letting the parameters $\lambda_{N}$ and $\gamma$ take random values on the range, $[0.0001,0.008]$ days $^{-1}$ and $\left[7 \times 10^{-9}, 10^{-7}\right]$ days $^{-1}$. cells ${ }^{-1}$, respectively. Ranges were chosen from the parameters obtained when fitting volumetric data.

\section{Discrete stochastic simulator}

A stochastic mesoscale BM growth simulator was developed based on Ref. [20]. SRS and the main biological processes occurring in response to treatment were incorporated into the model as described in Supplementary Information Section 2. To simulate tumor growth three cellular compartments were included: healthy cells, tumor cells and necrotic cells, and to describe the response to SRS, damaged tumor cells, activated immune cells and damaged healthy cells were added. Cells are discrete events and are allowed to undergo proliferation, apoptosis and migration to neighboring voxels. Mesoscale refers to a coarse-grained approach that works at the population level rather than that of individual cells reaching computationally clinically relevant BM sizes.

The spatial domain was set as a 3D grid discretized into cubic compartments (voxels) of side length $\Delta x$, fixed at $1 \mathrm{~mm}$. Each voxel has a specific dynamic that depends on its occupation and surroundings, and can contain several cells belonging to each cell population with an upper limit shown as local carrying capacity $K$. The different populations of cells will attempt to perform all available basic processes at each time step. These processes can be described by a binomial distribution with a probability associated with the process. That is, the number of cells successfully undergoing division, death, migration or transition to another population are calculated voxel-wise and state-wise at each time step, randomly sampling the corresponding binomial distribution, whose $N$ will be the number of cells in the population within a given voxel, and whose probability will be the rate of the process modulated by the time-step length $\Delta t$.

All processes, their probabilities and associated binomial distributions are thoroughly described in Supplementary Informatio Section 1. The study used sizes typically found in the clinical setting for the tumor sizes pre-SRS treatment, which are around $0.5-2 \mathrm{~cm}^{3}$ and the maximum tumor sizes up to $10 \mathrm{~cm}^{3}$. Hence, $L=60$ voxels per spatial length to make these sizes attainable. The time step was fixed at 4 hours. From typical cell sizes [51] the carrying capacity of a single voxel $N$ max was estimated to be $2 \times 10^{5}$ cells were selected and the same size was assumed for all type of cell. The choice of basal rates associated with biological processes were taken from different bibliographic sources and using a Bayesian criterion and are explained in detail in Supplementary Table S1.

The simulator was implemented in Julia (version 1.5.3). Simulation file processing and graphics were carried out in MATLAB (R2020b, MathWorks). Simulations were performed on a $2.7 \mathrm{GHz}$, Intel Core i7, 16 GB memory MacBook Pro machine.

\section{Ethical approval}

We have complied with all relevant ethical regulations. Human data were obtained in the framework of the study MetMath (Metastasis and Mathematics), a retrospective, multicenter, nonrandomized study approved by the corresponding institutional review boards. Animal care and experimental procedures were performed in accordance to the European Union and National guidelines for the use of animals in 


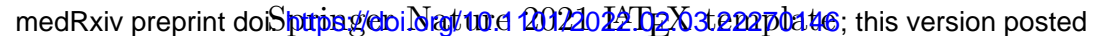

February 4, 2022. The copyright holder for this preprint (which was not certified by peer review) is the author/funder, who has granted medRxiv a license to display the preprint in perpetuity. All rights reserved. No reuse allowed without permission.

research and in accordance with a protocol approved by the CNIO and Comunidad de Madrid Institutional Animal Care and Use Committee (H2030-BrM3 cells).

Supplementary information. This article has an accompanying supplementary file.

Acknowledgments. This research has been supported by the James S. Mc. Donnell Foundation (USA) 21st Century Science Initiative in Mathematical and Complex Systems Approaches for Brain Cancer (Collaborative award 220020450, doi:10.37717/220020560), and by the Spanish Ministerio de Ciencia e Innovacin (grant PID2019-110895RB-100 funded by MCIN/AEI/ 10.13039/501100011033).

Competing interests. All authors declare no competing interests.

Availability of data and materials. All data that support the plots within this paper and other findings of this study are available from the corresponding author upon reasonable request.

Authors' contributions. Conceptualization: BO-T, JP-B, OL-T, EA, VMPG. Methodology: BO-T, OL-T, JJ-S, EA, JP-B, DM, VMP-G. Investigation: BO-T, JP-B, DM, OL-T, JJ-S, DA, AO-M, BA, MV, LZ, PG-G, LP-R, VMP-G, EA, EG-P, MLl, NC. Software: BO-T, OL-T, JP-B. Data curation: BO-T, JP-B, DM, VMP-G. Writing-Original draft: BO-T, VMP-G. Writing-Review and editing: BO-T, VMP-G, JP-B, OL-T. Supervision: JP-B, DM, EA, VMP-G. Project administration: VMP-G. Funding acquisition: VMP-G.

\section{References}

[1] Kuang, Y., Nagy, J. D. \& Eikenberry, S. E. Introduction to Mathematical Oncology. Chapman \& Hall/CRC. London (2016).

[2] Benzekry, S. et al., Classical mathematical models for description and prediction of experimental tumor growth. PLoS Comput Biol. 10(8), e1003800 (2014).

[3] Jarrett, A. M. et al., Mathematical models of tumor cell proliferation: A review of the literature. Expert Rev Anticancer Ther. 18(12), 1271-1286 (2018).

[4] P. Gerlee, The model muddle: In search of tumor growth laws. Cancer Res. 73(8), 2407-2411 (2013).

[5] West, J,., \& Newton, P.K., Cellular interactions constrain tumor growth. Proc Natl Acad Sci U S A.. 116(6), 1918-1923 (2019).

[6] Stensjoen, A.L., Solheim, O., Kvistad, K.A., Haberg, A.K., Salvesen, O., Berntsen, E.M., Growth dynamics of untreated glioblastomas in vivo. Neuro Oncol. 17(10), 14021411 (2015).

[7] Talkington, A. \& Durrett, R., Estimating tumor growth rates in vivo. Bull Math Biol. 77(10), 1934-1954 (2015). 


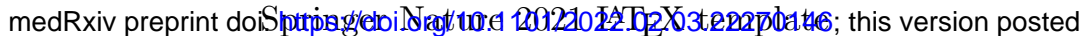

February 4, 2022. The copyright holder for this preprint (which was not certified by peer review) is the author/funder, who has granted medRxiv a license to display the preprint in perpetuity. All rights reserved. No reuse allowed without permisssion. The Macroscopic Growth Laws of Brain Metastases

[8] Pérez-García, V.M. et al. , Universal scaling laws rule explosive growth in human cancers. Nature Phys. 16, 12321237 (2020).

[9] Achrol, A.S. et al., Brain metastases. Nature Rev Dis Primers. 5(1), 5 (2019).

[10] Nayak, L., Lee, E.Q., Wen, P.Y., Epidemiology of brain metastases. Curr Oncol Rep. 14(1), 4854 (2012).

[11] Furuse, M. et al. , Radiological diagnosis of brain radiation necrosis after cranial irradiation for brain tumor: a systematic review. Radiat Oncol. 14(1), 28 (2019).

[12] Chuang, M.T., Liu, Y.S., Tsai, Y.S., Chen, Y.C. \& Wang, C.K., Differentiating radiation-induced necrosis from recurrent brain tumor using MR perfusion and spectroscopy: A meta-analysis. PLoS One. 11(1), e0141438 (2016).

[13] Vellayappan B. et al., Diagnosis and management of radiation necrosis in patients with brain metastases. Front Oncol. 8, 395 (2018).

[14] Lee, D., Riestenberg, R.A., Haskell-Mendoza, A., Bloch, O., Brain metastasis recurrence versus radiation necrosis: Evaluation and treatment. Neurosurg Clin N Am. 31(4), 575-587 (2020).

[15] Von Bertalanffy L., Quantitative laws in metabolism and growth. Q Rev Biol. 32(3), 217-231 (1957).

[16] Dagogo-Jack, I., Shaw, A.T., Tumour heterogeneity and resistance to cancer therapies. Nat Rev Clin Oncol. 15(2), 8194 (2018).

[17] Griffith, M. et al. , Optimizing cancer genome sequencing and analysis. Cell Syst. 1(33), 210-223 (2015).

[18] Klein, C., Selection and adaptation during metastatic cancer progression. Nature. 501, 365372 (2013).

[19] Ding, L. et al. , Clonal evolution in relapsed acute myeloid leukaemia revealed by whole-genome sequencing. Nature. 481, 506510 (2012).

[20] Jimnez-Snchez J. et al., A mesoscopic simulator to uncover heterogeneity and evolutionary dynamics in tumors. PLoS Comput Biol. 17(2), e1008266 (2021).

[21] León-Triana O. et al., CAR T cell therapy in B-cell acute lymphoblastic leukaemia: Insights from mathematical models. Comm Nonlin Sci Numer Simul. 94, 105570 (2021). 


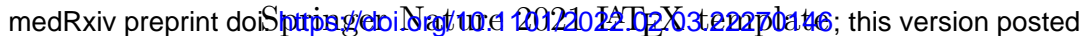

February 4, 2022. The copyright holder for this preprint (which was not certified by peer review) is the author/funder, who has granted medRxiv a license to display the preprint in perpetuity.

16 The Macroscopic Growth Laws of Brain Metastases

[22] Martnez-Rubio A. et al., A mathematical description of the bone marrow dynamics of CAR T-cell therapy in B-cell childhood acute lymphoblastic leukemia. Int J Mol Sci. 22(12), 6371 (2021).

[23] Jiang, T. et al. , Characterization of evolution trajectory and immune profiling of brain metastasis in lung adenocarcinoma. NPJ Precis Oncol. $\mathbf{5}(1), 6(2021)$.

[24] Brastianos, P. K. et al. , Genomic characterization of brain metastases reveals branched evolution and potential therapeutic targets. Cancer Discov. 5(11), 11641177 (2015).

[25] Wang, H. et al. , Genes associated with increased brain metastasis risk in non-small cell lung cancer: comprehensive genomic profiling of 61 resected brain metastases versus primary non-small cell lung cancer (Guangdong Association Study of Thoracic Oncology 1036). Cancer. 125(20), 35353544 (2019).

[26] Sun, J. et al. , Genomic signatures reveal DNA damage response deficiency in colorectal cancer brain metastases. Nat Commun. 10(1), 3190 (2019).

[27] Diossy, M. et al. , Breast cancer brain metastases show increased levels of genomic aberration-based homologous recombination deficiency scores relative to their corresponding primary tumors. Ann Oncol. 29(9), 19481954 (2018).

[28] Orozco, J.I.J. et al. , Epigenetic profiling for the molecular classification of metastatic brain tumors. Nat Commun. 9(1), 4627 (2018).

[29] Marzese, D.M. et al., DNA methylation and gene deletion analysis of brain metastases in melanoma patients identifies mutually exclusive molecular alterations. Neuro Oncol. 16(11), 14991509 (2014).

[30] Ortega-Sabater, C. , Calvo, G. F. \& Pérez-García,V. M. , Stochastic fluctuations drive non-genetic evolution of proliferation in clonal cancer cell populations. bioRxiv. doi: https://doi.org/10.1101/2021.06.08.447479 (2021).

[31] Gatenby, R.A., Zhang, J. \& Brown, J.S., First strikesecond strike strategies in metastatic cancer: Lessons from the evolutionary dynamics of extinction. Cancer Res. 79(13), 3174-3177 (2019).

[32] Gatenby, R.A., Artzy-Randrup, Y., Epstein, T., Reed, D.R., Brown, J.S., Eradicating Metastatic Cancer and the Eco-Evolutionary Dynamics of Anthropocene Extinctions. Cancer Res. 80(3), 613-623 (2020). 


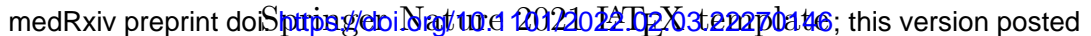

February 4, 2022. The copyright holder for this preprint (which was not certified by peer review) is the author/funder, who has granted medRxiv a license to display the preprint in perpetuity.

All rights reserved. No reuse allowed without permission.

The Macroscopic Growth Laws of Brain Metastases

[33] Priego, N. et al. , STAT3 labels a subpopulation of reactive astrocytes required for brain metastasis. Nat Med. 24(7), 10241035 (2018).

[34] Suh, J.H., Kotecha, R,. Chao, S.T., Ahluwalia, M.S., Sahgal, A. \& Chang, E.L., Current approaches to the management of brain metastases. Nat Rev Clin Oncol. 17(5), 279299 (2020).

[35] West, G.B., Brown, J.H. \& Enquist, B.J., A general model for ontogenetic growth. Nature. 413(6856), 628-631 (2001).

[36] Ellingson, B.M. et al., Consensus recommendations for a standardized brain tumor imaging protocol in clinical trials. Neuro Oncol. 17(9), 11881198 (2015).

[37] Bronnimann, C. et al., Interval between planning and frameless stereotactic radiosurgery for brain metastases: are our margins still accurate? Neurooncol Pract. 7(2), 211-217 (2020)

[38] Garcia, M.A. et al., Brain metastasis growth on preradiosurgical magnetic resonance imaging. Pract Radiat Oncol. 8(6), e369-e376 (2018).

[39] Kutuk, T. et al., Impact of MRI timing on tumor volume and anatomic displacement for brain metastases undergoing stereotactic radiosurgery. Pract Radiat Oncol. 8(6), 674-683 (2021).

[40] Nicholls, L.W. et al., Radiological kinetics of brain metastases and clinical implications for patients treated with stereotactic radiosurgery. Clin Oncol (R Coll Radiol). 31(1), 34-40 (2019).

[41] Semonche, A., Patel, N., Yang, I. \& Danish, S., Identification and Management of Progressive Enhancement After Radiation Therapy for Brain Metastases: Results from a Neurosurgical Survey. World Neurosurg. 139, e526-e540 (2020).

[42] Le Rhun, E. et al., EANO-ESMO Clinical Practice Guidelines for diagnosis, treatment and follow-up of patients with brain metastasis from solid tumours. Ann Oncol. 32(11), 1332-1347 (2021).

[43] Pestalozzi, B.C. \& Brignoli, S. , Trastuzumab in CSF. J Clin Oncol. 18(11), 23492351 (2000).

[44] Stemmler, H.J., Schmitt, M., Willems, A., Bernhard, H., Harbeck, N. \& Heinemann, V. , Ratio of trastuzumab levels in serum and cerebrospinal fluid is altered in HER2-positive breast cancer patients with brain metastases and impairment of blood-brain barrier. Anticancer Drugs. 18(1), 2328 (2007). 


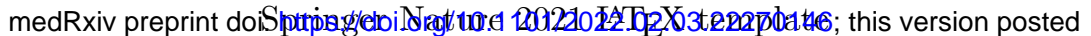

February 4, 2022. The copyright holder for this preprint (which was not certified by peer review) is the author/funder, who has granted medRxiv a license to display the preprint in perpetuity.

18 All rights reserved. No reuse allowed without permission.

[45] Lin, N.U. et al., Response assessment criteria for brain metastases: proposal from the RANO group. Lancet Oncol. 16(6), e270-e278 (2015).

[46] Park M. et al. , Clinical experience of Bevacizumab for radiation necrosis in patients with brain metastasis. Brain Tumor Res Treat. 8(2), 93-102 (2020).

[47] Pérez-Beteta J, et al., Tumor surface regularity at MR Imaging predicts survival and response to surgery in patients with Glioblastoma. Radiology. 288, 218-225 (2018).

[48] Nguyen, D. X. et al. , WNT/TCF signaling through LEF1 and HOXB9 mediates lung adenocarcinoma metastasis. Cell. 138, 5162 (2009).

[49] Mkango, S.B., Shaban, N., Mureithi, E. \& Ngoma, T., Dynamics of breast cancer under different rates of chemoradiotherapy. Comput Math Methods Med, 5216346 (2019).

[50] Villasana, M. \& Radunskaya, A., A delay differential equation model for tumor growth. J Math Biol. 47(3), 270-294 (2003).

[51] Milo, R., Jorgensen, P., Moran, U. \& Weber, G., BioNumbersthe database of key numbers in molecular and cell biology. Nucleic Acids Res 38, D750D753 (2009). 


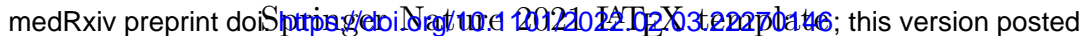

February 4, 2022. The copyright holder for this preprint (which was not certified by peer review) is the author/funder, who has granted medRxiv a license to display the preprint in perpetuity. All rights reserved. No reuse allowed without permission.
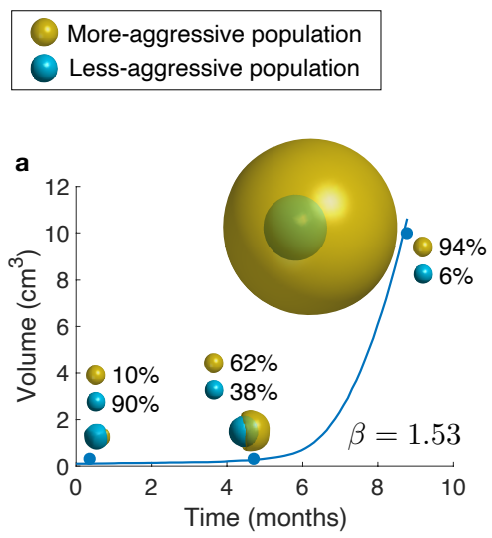

b

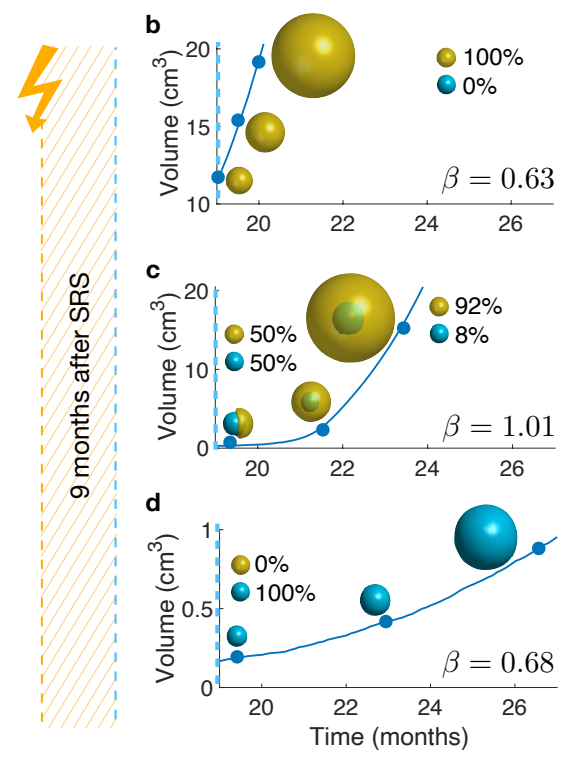

Fig. 2 Simulations of longitudinal growth of heterogeneous BMs with two initial populations (turquoise: less aggressive, and ocher: more aggressive). (a) pre-treatment and (b,c,d) post-treatment cases. The more aggressive population carries an advantage of $80 \%$ in proliferation speed and $92.5 \%$ in migration speed, compared to the less aggressive population. In (a) the BM is composed of $10 \%$ of more aggressive cells, and $90 \%$ of less aggressive cells. After eight months, the more aggressive population has overcome its counterpart, becoming dominant. Then, three different situations that can happen after treatment are illustrated: (b) the less aggressive population is completely removed from the tumor; (c) both populations remain in a balanced state, and (d) the more aggressive population is completely removed from the tumor. The betas were computed by choosing a random time point from each third of the total simulated time and are shown on each subplot. 


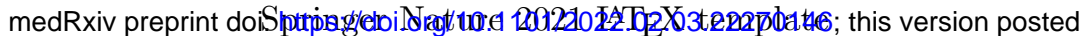

February 4, 2022. The copyright holder for this preprint (which was not certified by peer review) is the author/funder, who has granted medRxiv a license to display the preprint in perpetuity.

All rights reserved. No reuse allowed without permission. The Macroscopic Growth Laws of Brain Metastases
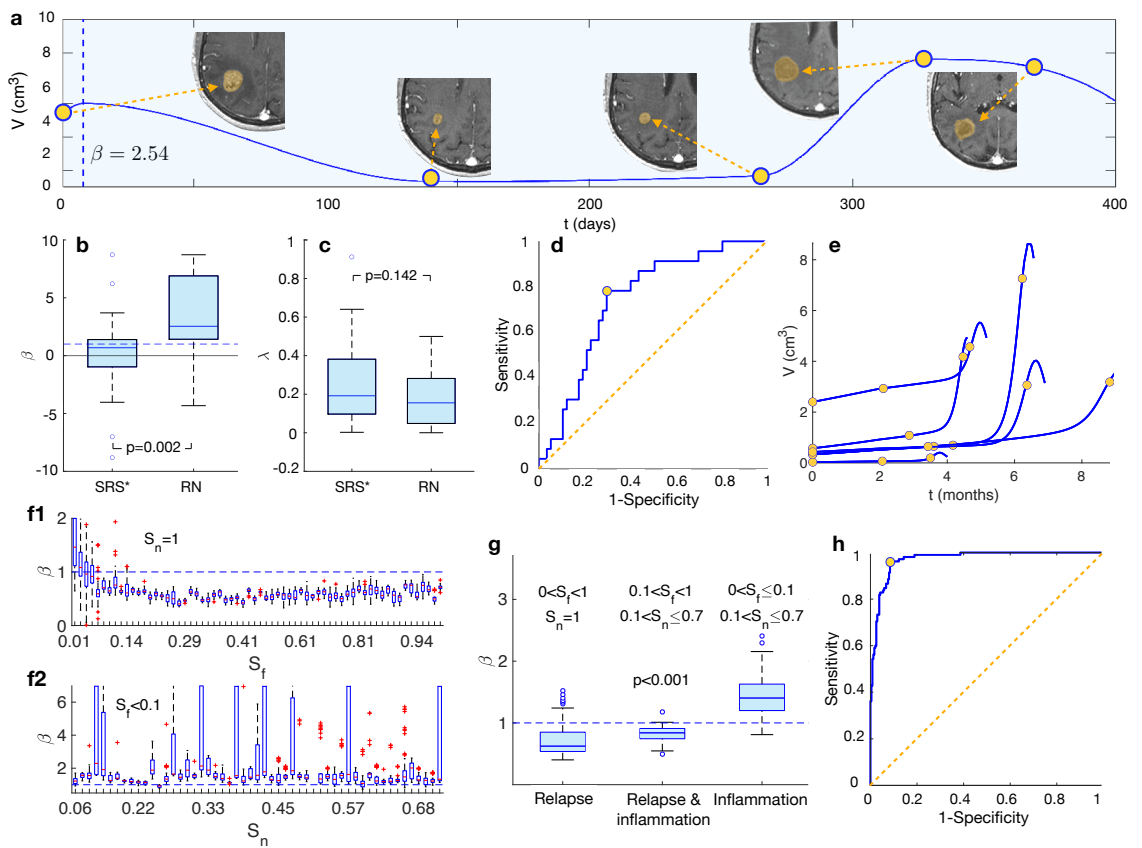

Fig. 3 a. Longitudinal dynamics of an irradiated BM diagnosed with RN. b. Box plots showing the comparison of the growth exponents $(\beta)$ obtained for recurrence post-SRS of BMs (SRS*, $N=40)$ versus RN events $(N=24)$. c. Box plots showing the growth rates $\lambda$ obtained for the same subgroups by an exponential fit (Eq. (4). p-values shown in (b,c) correspond to the result of the Kruskal-Wallis test. d. ROC curve for the discrimination between relapsing BMs and RN. e. Solutions for the longitudinal dynamics using the mathematical model in (7) (solid blue lines) and volumetric data (yellow dots) for six BMs diagnosed with RN. f. Comparison of box plots for the growth exponents $\beta$ calculated for virtual BMs. f1. Simulations with $S_{n}=1$ and $0<S_{\hat{f}}<1$. f2. Simulations with $0.1 \leq S_{n} \leq 0.7$ and $0<S_{\hat{f}} \leq 0.1$. g) Box plots showing the comparison of the growth exponents $\hat{\beta}$ between the different simulated BMs: relapse group (R), whose response is characterized by tumor progression $\left(0<S_{\hat{f}}<1, S_{n}=1\right)$, relapse and inflammation group (R \& I), whose response is characterized by tumor progression and inflammation $\left(0.1<S_{\hat{f}}<1,0.1 \leq S_{n} \leq 0.7\right)$ and inflammation group (I), whose response is characterized by inflammation $\left(0<S_{\hat{f}} \leq 0.1\right.$, $0.1 \leq S_{n} \leq 0.7$ ). h) ROC curve for the discrimination between tumor progression (R and $\mathrm{R} \& \mathrm{I}$ groups) and inflammatory response (I group) according to the growth exponent $\hat{\beta}$. 


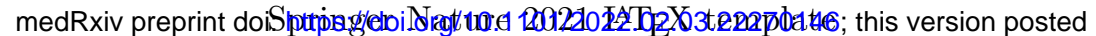

February 4, 2022. The copyright holder for this preprint (which was not certified by peer review) is the author/funder, who has granted medRxiv a license to display the preprint in perpetuity.

22 The Macroscopic Growth Laws of Brain Metastases
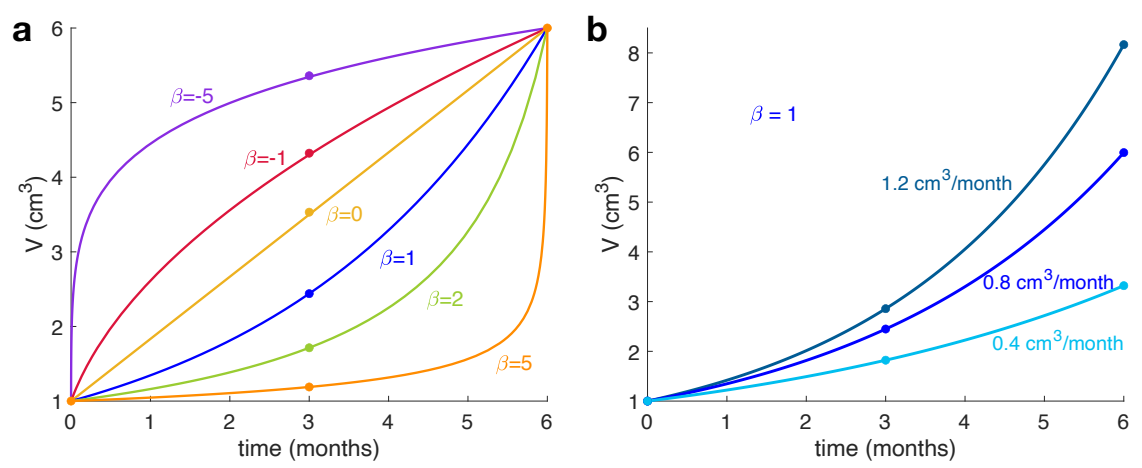

Fig. 4 Meaning of the growth exponent $\beta$. a. Growth behavior for several values of the growth exponent $\beta$ when fixing initial and final volumes and times. The growth exponent gives information about the shape of the curves. b. Growth behavior when fixing $\beta$ and the initial volume, showing different growth curves with different growth rates but the same exponent. 